\title{
Comparison of Gain Measurement Techniques for Characterization of Quantum Dot Lasers
}

\author{
HIFSA SHAHID* \\ RECEIVED ON 08.04.2015 ACCEPTED ON 16.09.2015 \\ ABSTRACT
}

\begin{abstract}
This paper presents a comparative analysis of three gain measurement methods which are H\&P (Hakki \& Paoli), SC (Segmented-Contact) and IA (Integrated-Amplifier) for the gain characterization of 1300nm (O-band) InAs/GaAs QD (Quantum Dot) laser devices. In this case, during continuous mode operation at a fixed heat-sink temperature of $17^{\circ} \mathrm{C}$, the experimental conditions, measured spectral ranges and signal to noise ratio are compared and advantages are discussed. The devices used for the analysis are fabricated as multi-section, single mode structures. Before self-heating, each of the methods show identical results but SC proved to be better in terms of accuracy of internal loss measurement. The H\&P method has been shown the only choice for high current density gain measurements at a fixed junction temperature under consideration. The method to remove self-heating effects via $\mathrm{H} \& \mathrm{P}$ is also discussed and via this method a high current density gain analysis upto $5.5 \mathrm{kA} / \mathrm{cm}^{2}\left(\sim 8 \mathrm{e}-\mathrm{h}\right.$ pairs)is performed under $30^{\circ} \mathrm{C}$ fixed junction temperature condition. In comparison to other methods, the IA method has shown to be advantageous in terms of low current density measurements exhibiting the capability of accessing wider spectral ranges and performing the gain characterization where laser material operates in loss.
\end{abstract}

Key Words: Hakki \& Paoli, Segmented-Contact Method, Integrated-Amplifier, Net Modal Gain, Quantum Dot.

\section{INTRODUCTION}

$\mathrm{T}$ he commercial applications of QD laser devices in the areas of optical coherence tomography [1], fiber optic: O-band communication [2] is largely due to their cost effectiveness and temperature independent turn on [3-4]. An understanding of the spectral relationship between gain and current density is not only integral to the device engineering but also crucial to determine the performance of semiconductor laser devices [5].

Optical gain measurement is a fundamental requirement for the characterization of lasers and amplifiers owing to its usefulness in the determination of their various static and dynamic [6] characteristics. The commonly derived information from the gain spectra such as threshold current density, modulation characteristics [7], line-width enhancement factor [8], carrier distribution among the dots and configuration of higher order states [9] play an important role towards device engineering [10]. The accurate measurement of the gain spectrum is therefore needed to assist in the physical understanding of laser materials and heterostructures. Due to the be-spoke laser device structure requirements these techniques are not compared before.

* Department of Electrical Engineering, University of Engineering \& Technology, Kala Shah Kaku Campus, Lahore.

Mehran University Research Journal of Engineering \& Technology, Volume 35, No. 4, October, 2016 [p-ISSN: 0254-7821, e-ISSN: 2413-7219] 
This paper presents a comparative, empirical analysis of H\&P [11], SC [12] and IA methods [13] for gain measurement. The analysis being presented here would mainly contribute towards the understanding of many body effects at high carrier/current densities and evolution of states at comparatively lower carrier/current densities. This is made possible by utilizing various InAs/ GaAs 1.3 $\mu \mathrm{m}$ QD laser materials (commercial \& bi-layer), via fabricating multi-section single mode laser device structures which are studied under CW (Continuous Wave) operation at a constant heat sink temperature of $17^{\circ} \mathrm{C}$. Furthermore, the conditional superiority of the gain measurement methods is also discussed in terms of removal of self heating effects.

\section{DEVICE STRUCTURE AND FABRICATION}

The QD laser structure fabricated for the analysis as shown in Fig. 1(a) is grown by Innolume. In this case ten QD layers are grown as a core on $\mathrm{n}-\mathrm{Al}_{0.35} \mathrm{Ga}_{0.65} \mathrm{As}$ cladding layer and on the top of the core an $\mathrm{p}-\mathrm{Al}_{0.35} \mathrm{Ga}_{0.65} \mathrm{As}$ cladding layer is deposited. Each of the core layer comprises of alternating layers of GaAs then InAs QD layer and $\mathrm{In}_{0.35} \mathrm{Ga}_{0.65} \mathrm{As}$ as strain reducing layer. Whole of the structure is grown upon 500nm n-GaAs substrate and is finished by $200 \mathrm{~nm}$ p-GaAs layer.

Then, the laser structure is fabricated as multi-section narrow ridge laser devices with deep etch having each section width as $3 \mu \mathrm{m}$ and length as $500 \mu \mathrm{m}$.

A bi-layer InAs/GaAs QD laser structure as shown in Fig. 1(b) was used for the gain comparison at low current densities. The structure comprises five pairs of closelystacked QD layers. The small separation (10 nm GaAs) between the paired layers results in preferential nucleation of QDs in the second layer above QDs in the first (seed) layer, so that the seed layer acts as a base for QD growth in the second layer, which fixes the QD density [14]. This allows suitable growth conditions for the second QD layer to be chosen to achieve an extension in room temperature emission from the $\mathrm{QD}$ ground state beyond $1300 \mathrm{~nm}$ while maintaining a reasonable QD density. The small separation between the paired layers allows efficient electronic coupling between the layers so that emission occurs from the second, longwavelength QD layer. Full details of the epitaxial structure are provided elsewhere [15].

\section{THEORY}

\subsection{Hakki \& Paoli Method}

The H\&P [11] is a technique by which gain of the material can be predicted and is applicable to only narrow ridge, single mode devices. Furthermore, a special fabrication process is not required in this case. It is a round trip method and can be used only below lasing to perform the spectral gain measurements therefore it requires short length, non lasing laser devices to characterize the material. The laser cavity length must be small enough allowing the complete resolution of the Fabry-Pérot longitudinal modes.

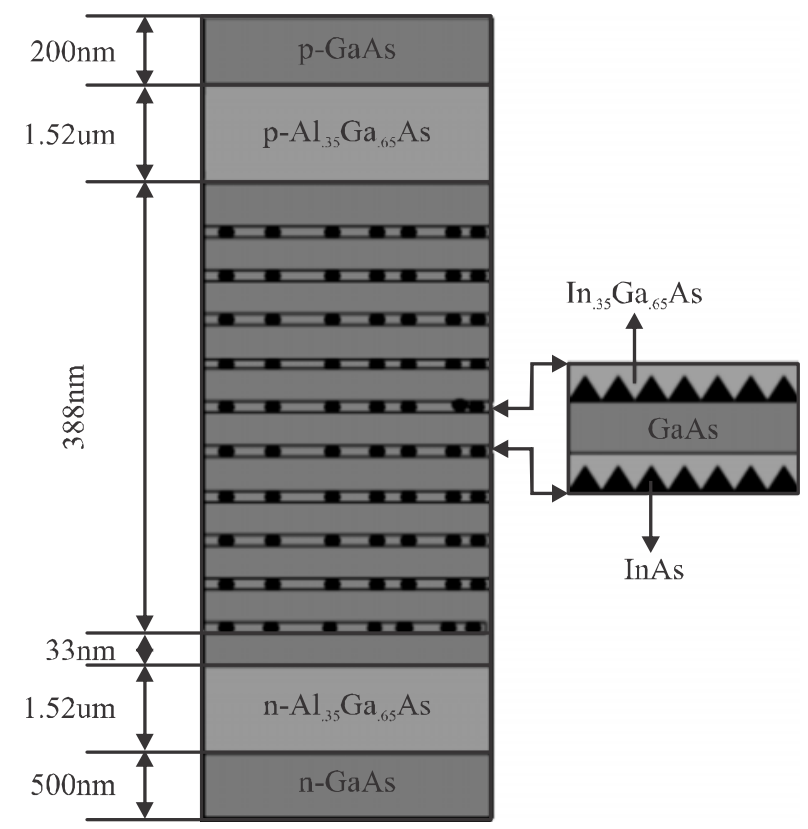

FIG. 1(a). INNOLUME AS GROWN VIA MOLECULAR BEAM $\operatorname{EPITAXY(MBE)}$

Mehran University Research Journal of Engineering \& Technology, Volume 35, No. 4, October, 2016 [p-ISSN: 0254-7821, e-ISSN: 2413-7219] 
The modulation depth, as calculated by knowing the peak and trough of the electro-luminescence spectra allows the gain to be calculated as a function of each of the wavelengths. Due to high spectral resolution requirements for the method the signal to noise ratio is low. The gain values obtained become unreliable when troughs approach the noise floor. These factors result in longer data acquisition times and make low current density measurements very difficult. Fig. 2 shows the modulation depth an electro-luminescence spectrum and can be calculated by Equation (1) [11].

In case of H\&P method the net modal gain at each wavelength can be calculated via Equation (2) [11]. Other than modulation depth modal gain shows its dependence upon the laser cavity length and the reflectivity at facets which is usually $33 \%$.

$\gamma_{\mathrm{i}}=$ Modulation Depth $=\frac{\mathrm{P}_{\mathrm{i}}+\mathrm{P}_{\mathrm{i}+1}}{2 \mathrm{v}_{\mathrm{i}}}$

Net Modal Gain $=\frac{1}{\mathrm{~L}} \ln \left(\frac{\left(\gamma_{\mathrm{i}}^{\frac{1}{2}}\right)+1}{\left(\gamma_{\mathrm{i}}^{\frac{1}{2}}\right)-1}\right)+\frac{1}{\mathrm{~L}} \ln \mathrm{R}$
In order to accurately determine the modal gain it needs a fully resolved electro-luminescence spectrum. For the purpose the resolution was adjusted to be $10 \mathrm{pm}$ and electro-luminescence spectra are retrieved.

Fig. 3 indicates the experimental set up used for the H\&P analysis [5]. In this case a current source is used as an input to the laser device. The temperature controlled condition for the laser device under test is achieved via placing it on a heat sink with a feed back control system to

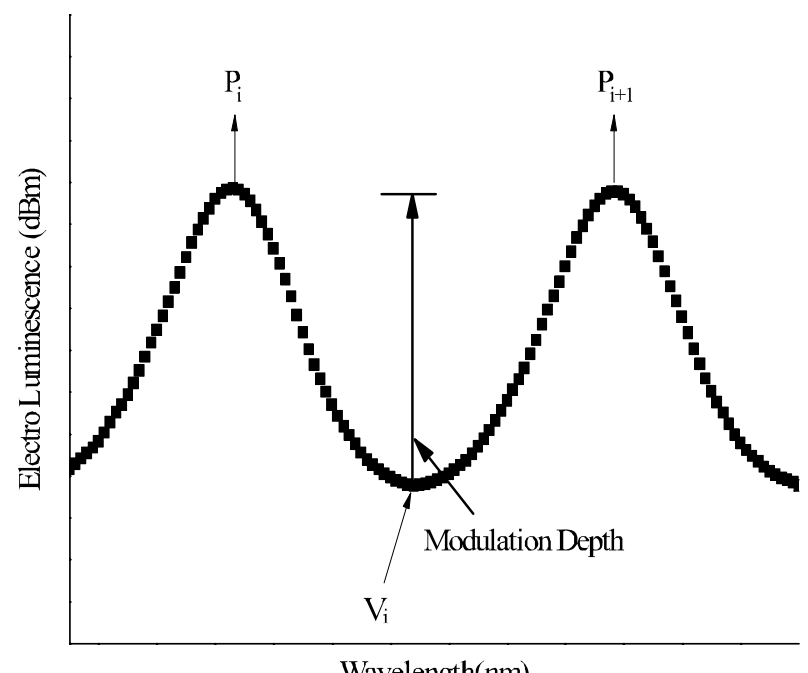

Wavelength(nm)

FIG. 2. AN ELECTRO-LUMINESCENCE SPECTRUM EXHIBITING THE MODULATION DEPTH OF FEBRY-PÉROT RESONANCES

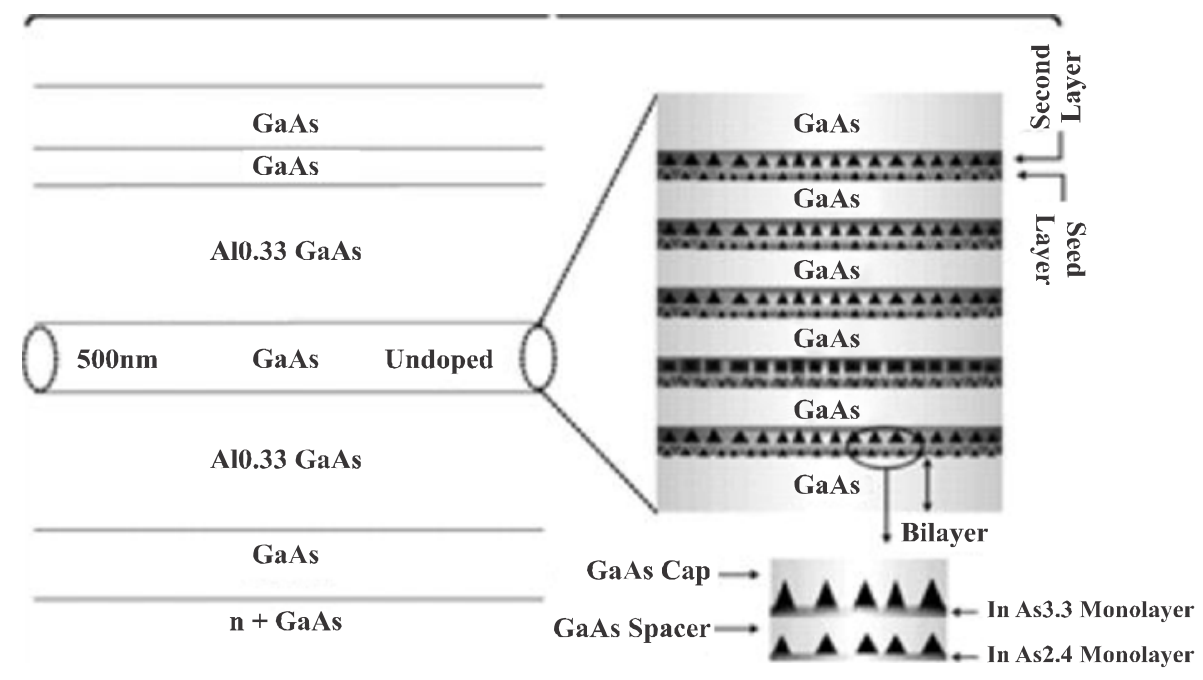

FIG. 1(b). BI-LAYER DEVICE EPITAXIAL LAYER STRUCTURE/LAYER SCHEMATICS

Mehran University Research Journal of Engineering \& Technology, Volume 35, No. 4, October, 2016 [p-ISSN: 0254-7821, e-ISSN: 2413-7219] 
maintain a required temperature at each current density level. A 3-axis tracking system is used which is feedback controlled and is placed before the laser device which moves the single mode lensed fiber and actively aligns it according to the maximum output power from the laser. $99 \%$ of the coupled power is sent to the optical spectrum analyzer and $1 \%$ is fed back to the tracking stage to remain aligned for the maximum input power.

\subsection{Segmented-Contact Method}

The schematic for pumping a multi-section device for SC gain measurement method [12] is shown in Fig. 4. In this case, the gain is evaluated via finding the ratio of the amplified spontaneous emissions obtained by pumping the sections of lengths $\mathrm{L}$ and $2 \mathrm{~L}$ with the same current density.

Via optical spectrum analyzer and utilizing the Lab-view as a data acquisition tool electro-luminescence spectra were retrieved from the sections as mentioned before which enabled the modal gain to be determined as given by Equation (3) [12].

Net Modal Gain $=\frac{1}{\mathrm{~L}} \ln \left(\frac{\mathrm{I}_{2 \mathrm{~L}}}{\mathrm{I}_{\mathrm{L}}}-1\right)$

Here $\mathrm{I}_{\mathrm{L}}$ and $\mathrm{I}_{2 \mathrm{~L}}$ are the amplified spontaneous emission from the sections of length $\mathrm{L}$ and $2 \mathrm{~L}$ respectively (Fig. 5).

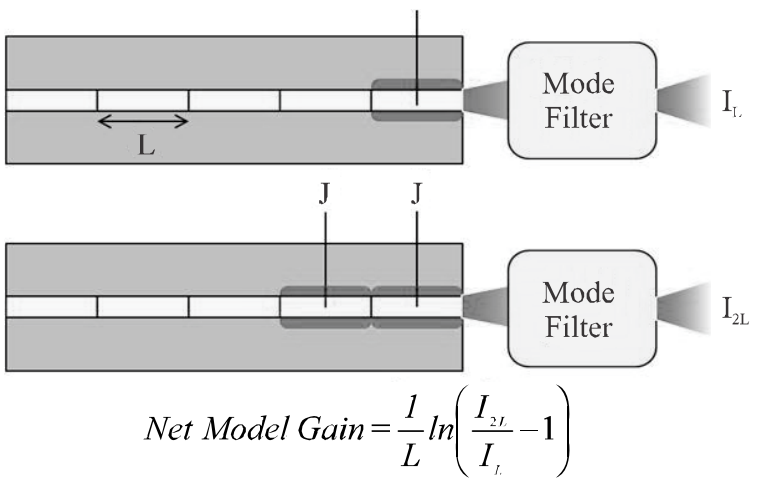

FIG. 4. THE DEVICE GEOMETRIES/SCHEMATICS FOR SC GAIN MEASUREMENT

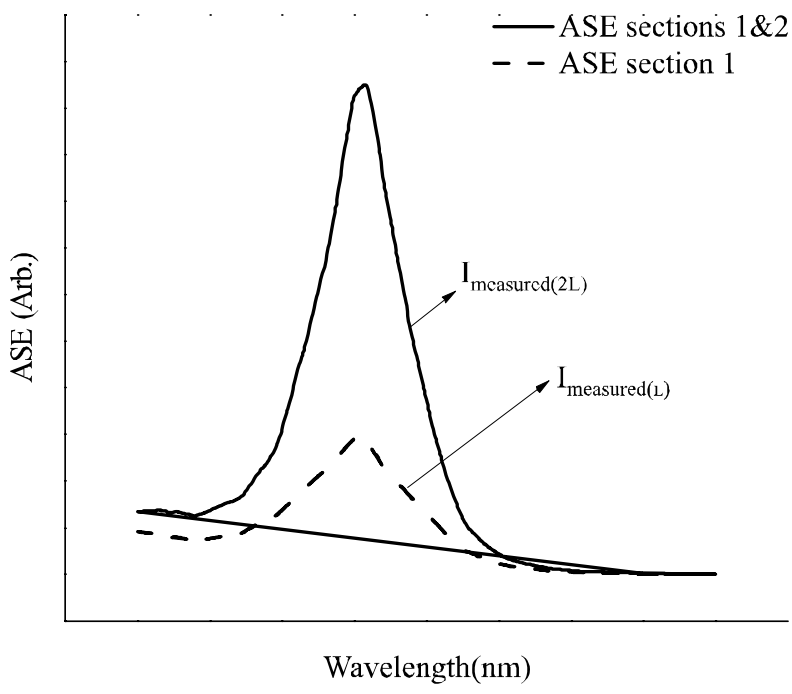

FIG. 5. AMPLIFIED SPONTANEOUS EMISSION FROM SECTION LENGTHS L AND $2 L$ OF A MULTI-SECTION LASER DEVICE DRIVEN AT THE SAME CURRENT DENSITY AT CONSTANT HEAT-SINK TEMPERATURE OF $17^{\circ} \mathrm{C}$ UNDER CW MODE OF OPERATION

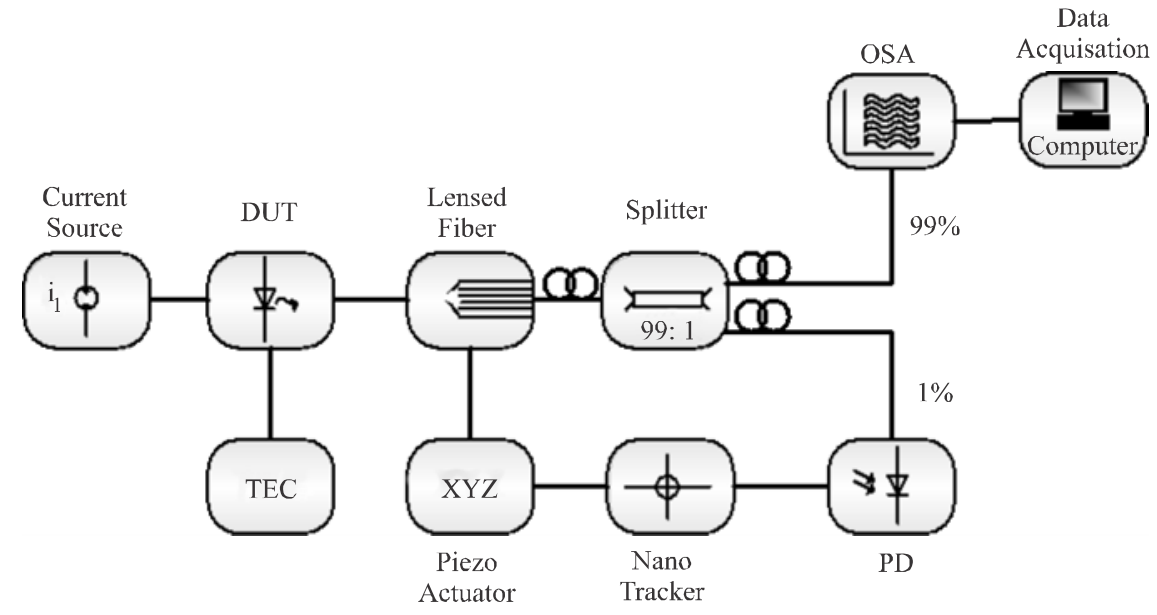

FIG. 3. THE EXPERIMENTAL SETUP FOR H\&P GAIN MEASUREMENT METHOD 
The SC gain measurement method is applicable to both multi-modal and single mode laser devices provided higher order modes are entirely eliminated by either spatial filtering [12] or an additional device length is left un-pumped [16] in the front of pumped sections. In our case the second option is used and an un-pumped section length of the order of $250 \mu \mathrm{m}$ is left at the front as an unguided spontaneous emission filter.

The measurement set up for the technique is shown in Fig. 6 [5]. This experimental schematic can be employed for both SC and IA gain measurement methods. As can be observed that the experimental set up requirements are less stringent than the H\&P. The difference mainly is that instead of single mode lensed fiber as in case of H\&P method, a multi-mode fiber is used. So, the alignment requirements are not very critical as in case of the H\&P method. Coupling efficiencies are also higher in comparison. Furthermore, less resolution data acquisition requirements make analysis much quicker than the H\&P method.

\subsection{Integrated-Amplifier Method}

The IA gain method [13] is a variant of SC method. Here its importance in predicting the gain of a QD laser device at low current/carrier densities is discussed. This method allows the gain spectrum to be measured at lower current densities where material usually operates in loss and therefore can act as an alternate method to quantitatively determine the absorption in the QD states. It has an additive advantage to access wider spectral ranges in comparison to existing conventional gain measurement techniques [11-12] as well.

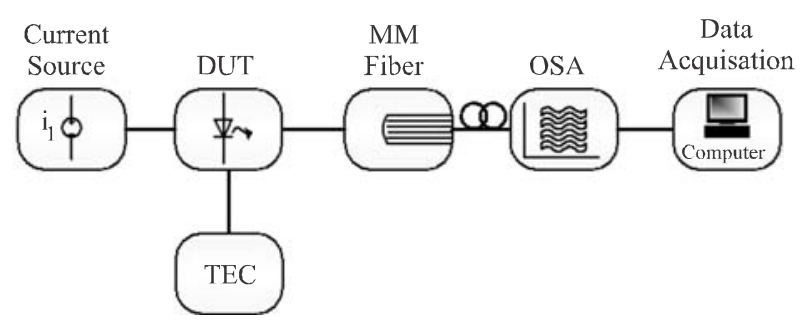

FIG. 6. THE EXPERIMENTAL SET UP FOR SEGMENTEDCONTACT/INTEGRATED-AMPLIFIER METHODS
For the SC method, the gain measurement can only be performed if two conditions are justified. According to the first condition the amplified spontaneous emission signal should be well above the measurement system noise floor and for the second condition the signals from $\mathrm{L}$ and $2 \mathrm{~L}$ section lengths should be distinguishable from each other. Usually at very low current densities, some part of the gain spectra cannot be retrieved as the optical signal for the wavelength range is lost in noise floor. This problem can be dealt with if somehow the signal could be elevated well above the noise floor. Hence, the signal above the noise floor is raised by use of the waveguide material and by pumping it with a suitable current density. By this not only the longer spectral ranges could be accessed but also absorption measurement could be performed conveniently. These measurements can further be used in characterization of the device material at low current densities. The measurement setup is same as for SC method as shown in Fig. 6. The difference mainly is the device geometry as shown in Fig. 7(a-c) i.e. in case of integrated amplifier method the front two section of the device are used as an amplifier and rest two are pumped in the same way as for the case of segmented contact method.
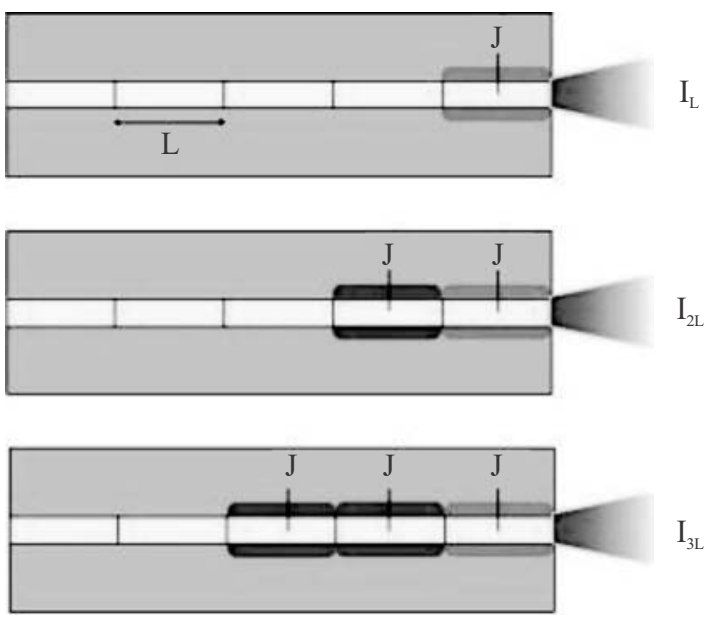

FIG. 7(a,b). THE DEVICE GEOMETRIES/SCHEMATICS FOR SEGMENTED-CONTACT GAIN MEASUREMENT (c) THE DEVICE GEOMETRY/SCHEMATIC FOR LOW CURRENT DENSITY GAIN MEASUREMENT

Mehran University Research Journal of Engineering \& Technology, Volume 35, No. 4, October, 2016 [p-ISSN: 0254-7821, e-ISSN: 2413-7219] 
It is important to note that for a fair comparison of the different methods an external mode filter is not employed for the SC method. This ensures that the light collection efficiency is same for all the cases.

In order to deduce the gain spectrum by integrated amplifier method, initially the emission spectrum with only the amplifier sections is measured, in our case this is with driving the front two contact segments at a current density of JA. This intensity, IA, is subtracted from the intensities IL (driving a single contact at a given current density) and I2L (driving two contacts at a given current density). The net modal gain in this case can be deduced using Equation (4) $[12]$ :

Net Modal Gain $=\frac{1}{\mathrm{~L}} \ln \left(\left(\frac{\mathrm{I}_{3 \mathrm{~L}}-\mathrm{I}_{\mathrm{A}}}{\mathrm{I}_{2 \mathrm{~L}}-\mathrm{I}_{\mathrm{A}}}\right)-1\right)$

\section{QUANTUM DOT LASER DEVICE SELECTION}

For sake of comparison between H\&P and SC methods at high current densities, the laser lengths were 'as cleaved' as $300 \mu \mathrm{m}$ and $4.75 \mathrm{~mm}$ respectively. In each of the cases, the laser cavity width was $3 \mu \mathrm{m}$. In first case

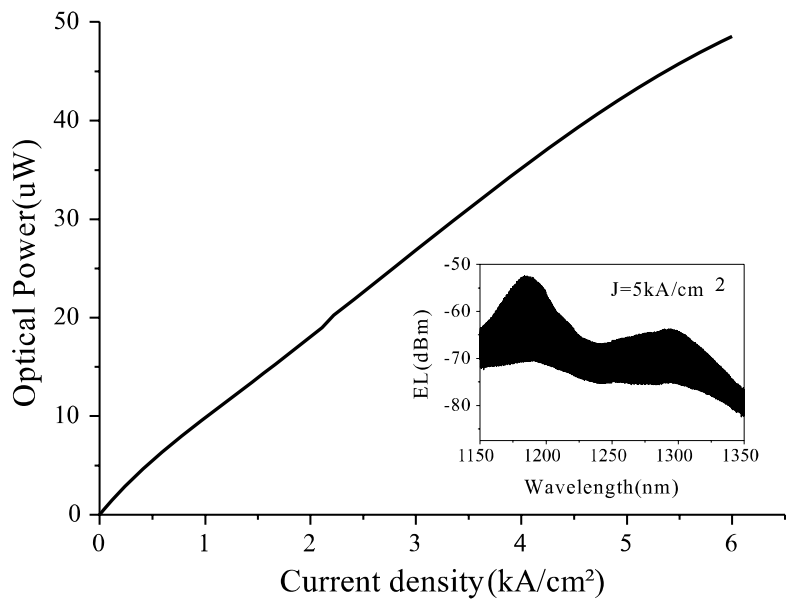

FIG. 8(a). OPTICAL POWER VS. CURRENT DENSITY (L-J) CHARACTERISTICS OF 300X3 $\mu \mathrm{m}$ INNOLUME QD LASER DEVICE FOR H\&P ANALYSIS. INSET: SHOWS ELECTROLUMINESCENCE FROM LASER DEVICE VIA EXHIBITING NON-LASING CHARACTERISTICS AT $5 \mathrm{kA} / \mathrm{cm}^{2}$ for H\&P method as shown in Fig. 8(a) optical power vs. current density characteristics confirms the non lasing characteristics of the laser device even at high current densities. This is further confirmed via electroluminescence characteristics as shown in the inset to Fig. 8(a) at $5 \mathrm{kA} / \mathrm{cm}^{2}$. For SC method the amplified spontaneous emissions from lengths, $\mathrm{L}$ and $2 \mathrm{~L}$ are shown in Fig. 8(b) at $5 \mathrm{kA} / \mathrm{cm}^{2}$ which also show the non-lasing characteristics in this case. Hence both of the devices were well suited for the empirical analysis.

For low current density measurement the SC and IA gain measurement techniques are compared. To fulfill the requirement a bi-layer multi-section device: $10 \mathrm{~mm}$ long, 7 ?m wide with $1 \mathrm{~mm}$ long isolated contacts was used. The multi-section device is shown in Fig. 9.

The I-V characteristics of the individual sections were essentially identical. It is therefore assumed that the L-J characteristics of the individual sections are also identical. All the acquisition parameters (resolution, sensitivity, integration times and coupling efficiency) were selected to be same for both techniques.

The amplified spontaneous emission characteristics for $\mathrm{SC}$ and IA are shown in inset to Fig. 8(b). For the latter case the amplifier section was derived at $1.42 \mathrm{kA} / \mathrm{cm}^{2}$.

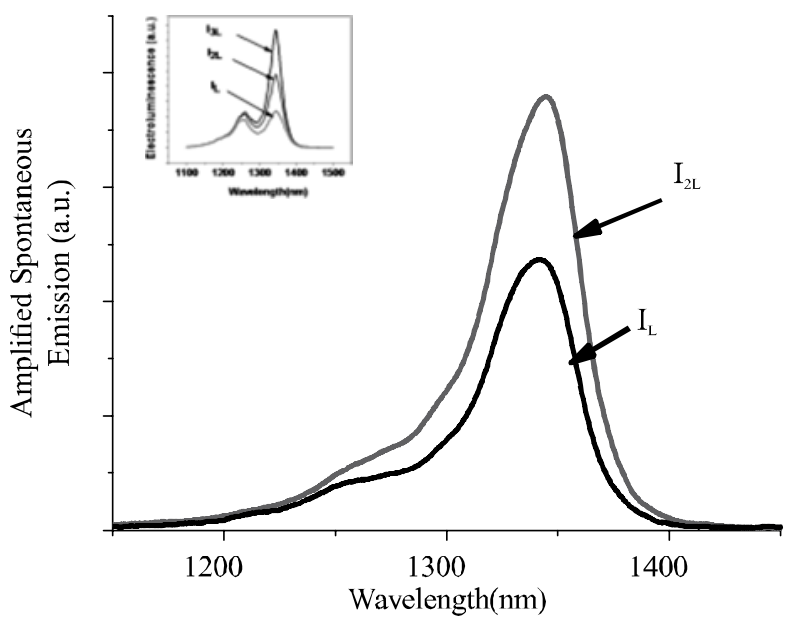

FIG. 8(b). AMPLIFIED SPONTANEOUS EMISSION FOR SECTION LENGTHS L AND 2L FOR SEGMENTED-CONTACT METHOD. INSET: SHOWS THE AMPLIFIED SPONTANEOUS EMISSION FOR INTEGRATED-AMPLIFIER METHOD

Mehran University Research Journal of Engineering \& Technology, Volume 35, No. 4, October, 2016 [p-ISSN: 0254-7821, e-ISSN: 2413-7219] 


\section{RESULTS AND DISCUSSION}

The comparative gain analysis at high current densities between H\&P and SC was performed in current density range: $0.03-1.67 \mathrm{kA} / \mathrm{cm}^{2}$ at a constant heat sink temperature of $17^{\circ} \mathrm{C}$ under $\mathrm{CW}$ operational mode.

For low current density comparison the techniques were tested out to access wider spectral ranges and absorption measurement. The bi-layer material was found to be more optically efficient in comparison to the Innolume material therefore was used to perform low current density analysis. The analysis was performed for the current density range: $7-300 \mathrm{~A} / \mathrm{cm}^{2}$.

\subsection{Net Modal Gain Empirical Comparison at High Current Densities}

Net modal gain spectra for H\&P and SC techniques for the given carrier density at a constant heat sink temperature of $17^{\circ} \mathrm{C}$ are shown in Fig. 10(a-b) respectively.

The comparative analysis [5] indicates an initial blue shift and then a red shift of the modal gain spectra. In this case the blue shift is attributable to the state filling effects [16] and red shift is due to the combined self heating and free carrier effects.

In case of H\&P method, net modal gain spectra are observed to be noisier towards shorter and longer wavelengths. This observed noise is attributable to the valleys of the electro-luminescence spectra touching the noise floor rendering the data unreliable. Hence a lesser signal to noise ratio towards these wavelengths is obtained.

In Fig. 10(b) for SC method, the internal loss (?i) value can be clearly identified at longer wavelengths in comparison to the H\&P method. This is attributable to the less resolution requirements for the method which not only improves the signal to noise ratio but also makes data acquisition times much shorter i.e. upto 15 times. Due to a higher signal to noise ratio achieved via this method, is suggestive of accessing lower current densities in comparison. Further suggestion towards fulfillment of the purpose is via longer integration times i.e. higher resolution settings in addition [5].

The overlapping comparative analysis of the two said techniques is performed before onset of self heating effects in Fig. 11. Fig. 11(a), at low current density range: 0.13-2$0.5 \mathrm{kA} / \mathrm{cm}^{2}$ shows identical results for both techniques with the net modal gain variation within the range of $\pm 0.5 / \mathrm{cm}$. However, the noisier H\&P net modal gain spectra make internal loss determination more difficult due to the valleys touching the acquisition system's noise floor which is not the case for the SC method. The same the case is observed for high current densities as shown in Fig. 11(b). In this case wider/more reliable net modal gain spactra are obtained in case of SC method comparison to the H\&P method.

With the on-set of self heating, the comparison of the techniques become impossible due to the different degree of self heating produced in the cavities due to the difference in their corresponding lengths.

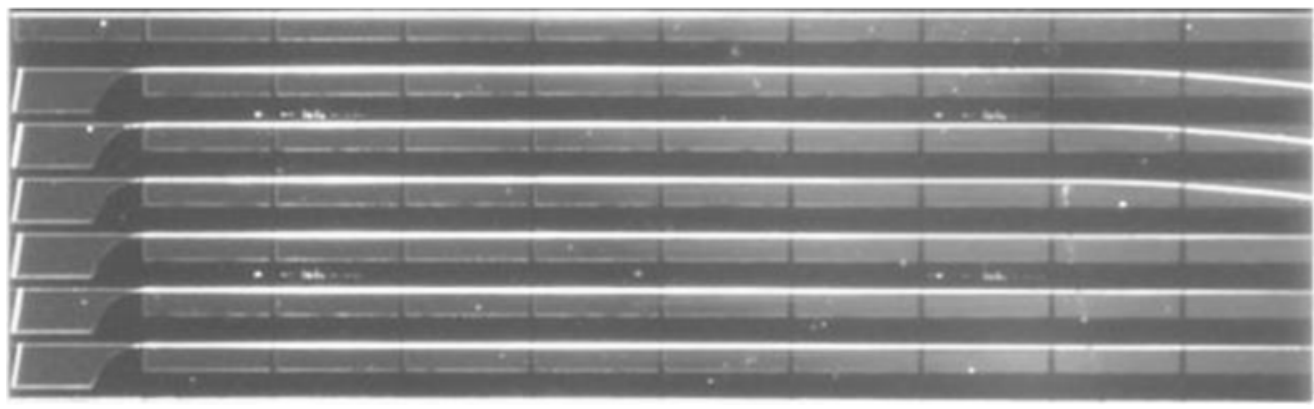

FIG. 9. THE MULTI-SECTION DEVICE SELECTED FOR THE COMPARATIVE EMPIRICAL GAIN ANALYSIS OF SEGMENTED-CONTACT AND INTEGRATED-AMPLIFER TECHNIQUES

Mehran University Research Journal of Engineering \& Technology, Volume 35, No. 4, October, 2016 [p-ISSN: 0254-7821, e-ISSN: 2413-7219] 
It is already known that via short length laser devices the longitudinal modes can be clearly resolved. Therefore, the H\&P method suggests the consideration of a single longitudinal mode as a junction temperature monitor to entirely remove the self heating/ Joule heating effects from the laser device making possible for laser devices to be analyzed for the free-carrier effects solely

\subsubsection{Temperature Calibration for Hakki \& Paoli Method}

The self heating effects are considered to play a major role in modifying the modal gain spectral results and mask other important effects to be analyzed. For the purpose, a

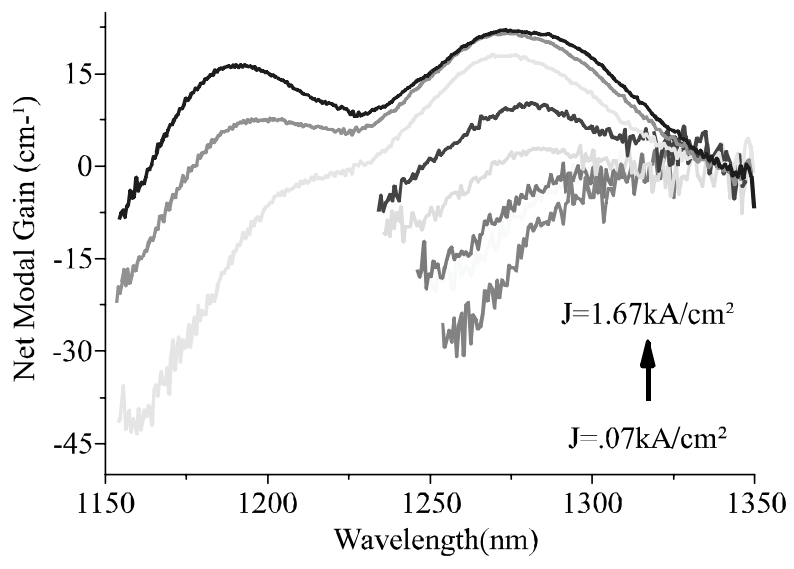

FIG. 10(a). CONTINUOUS WAVEHAKKI\& PAOLI

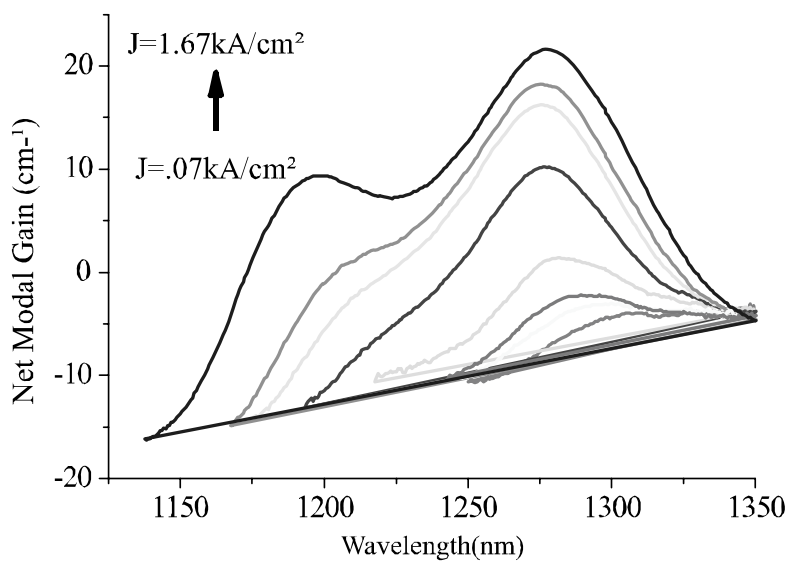

FIG. 10(b). SEGMENTED-CONTACT NET MODAL GAIN SPECTRA AS A FUNCTION OF CURRENT DENSITY AT $17^{\circ} \mathrm{C}$ FIXED HEAT SINK TEMPERATURE method [5] is presented here, via employing itself heating effects are entirely removed and device can be analyzed at a fixed junction temperature of interest even at high current densities. The steps employed for the method are clearly shown in Fig. 12.

The Fig. 12(a) plots the longitudinal mode peak position shift as a function of temperature in the range of 17.5$22^{\circ} \mathrm{C}$. Inset to Fig. 12(a) shows an actual shift of the single longitudinal mode for the same temperature range. A linear relationship of modal shift as function of temperature is

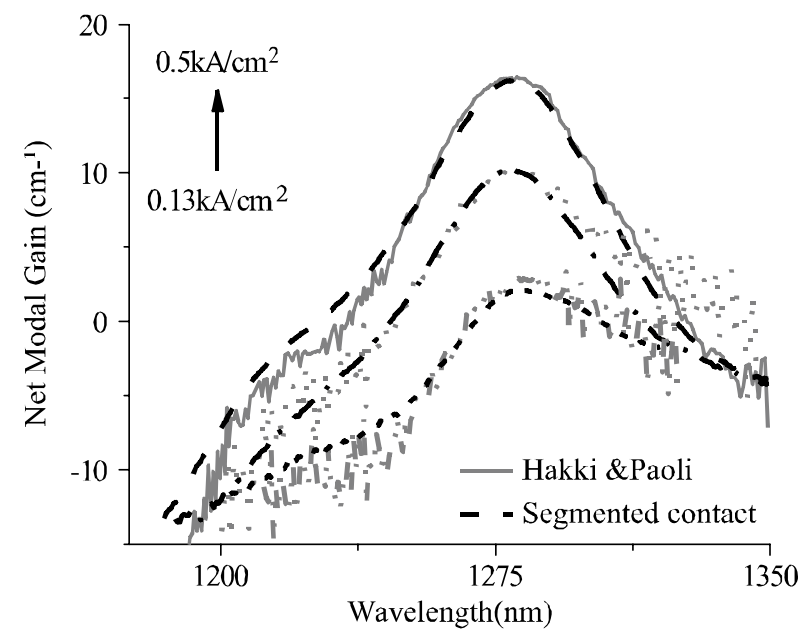

FIG. 11(a). A COMPARISON OF NET MODAL GAIN FOR H\&P AND SEGMENTED-CONTACT METHODS AT $17^{\circ} \mathrm{C}$ CONSTANT HEAT SINK TEMPERATURE

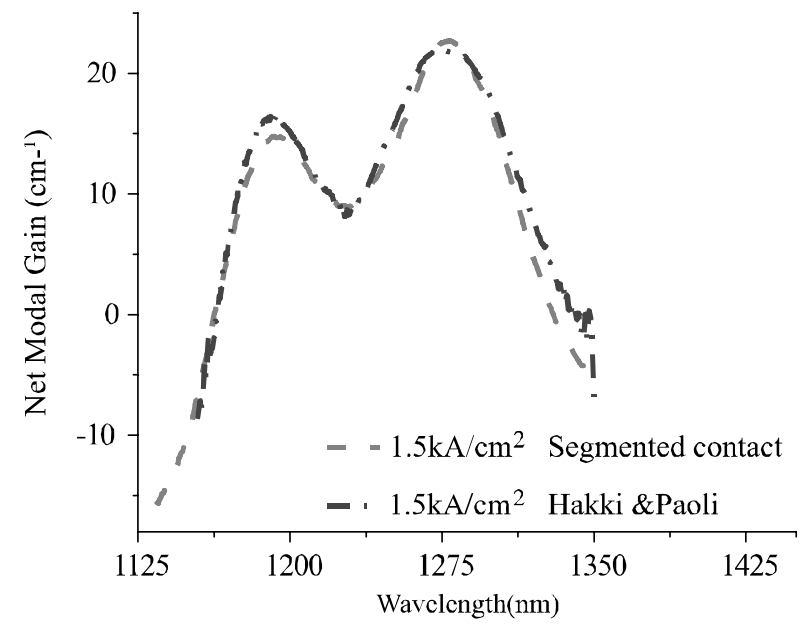

FIG. 11(b). DIFFERENT DEGREE OF SELF HEATING IN THE LASER DEVICES FOR H\&P \& SEGMENTED-CONTACT METHOD SHOWING DIFFERENT SPECTRAL SHAPES 
observed. It is attributable to the laser length elongation or may be due to refractive index variation as a function of temperature.

The inset to Fig. 12(b) plots the same Fabry-Pèrot mode's shift as a function of current density. A quadratic trend in shift is indicative of dominant Joule heating effects. Then via these two plots the cavity temperature can be determined/plotted as function of current density which allows the re-adjustment of the temperature for each of the elevated current density value fixing the junction temperature at a fixed value of interest.

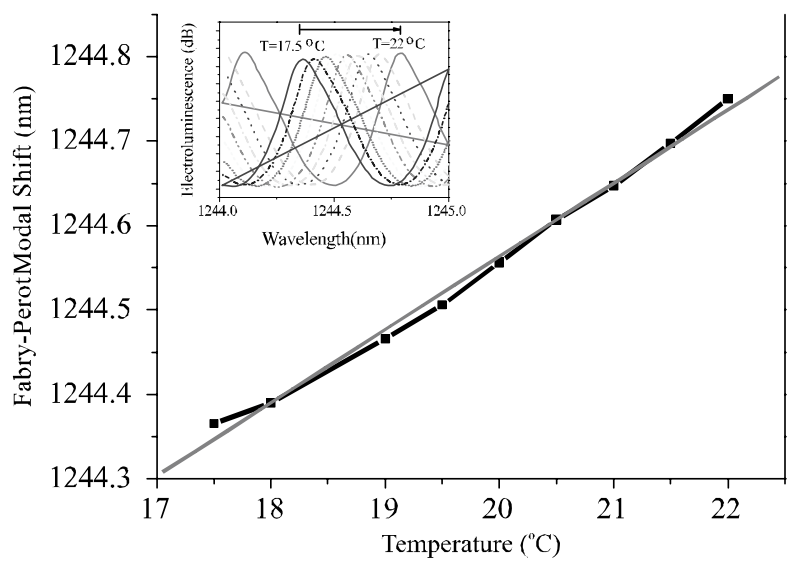

FIG. 12(a). A FEBRY-PAEROT PEAK POSITION SHIFTWITH TEMPERATURE. INSET PLOTS FABRY-PEROT MODAL SHIFT AS A FUNCTION OF TEMPERATURE

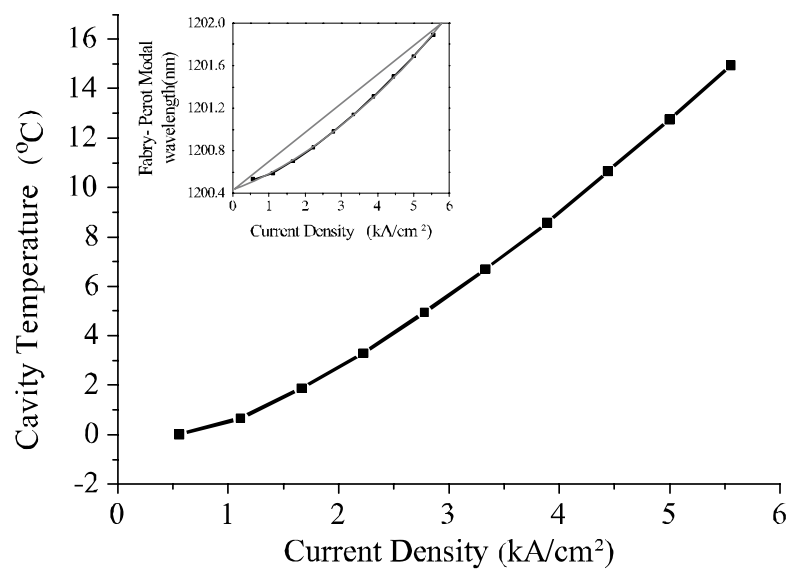

FIG. 12(b). CAVITY TEMPERATURE RISE AS A FUNCTION OF CARRIER DENSITY. INSET SHOWS FEBRY-PEROT MODAL SHIFT WITH CARRIER DENSITY
Via employing temperature calibration methodology, the gain spectra are plotted as shown in Fig. 13 upto high current densities such as $5.5 \mathrm{kA} / \mathrm{cm}^{2}$ at a constant junction temperature of $30^{\circ} \mathrm{C}$. In this case, the evolution of the gain spectra can be explained in terms of free carrier effects.

\subsection{Net Modal Gain Comparison at Low Current Densities}

Generally with SC method, the gain spectrum can only be determined at wavelengths at which spontaneous emission occurs. It may not be obtained over shorter wavelengths where spontaneous emission is week. The purpose of amplifier section is to compensate for loss providing the positive net modal gain in this spectral region. It may in turn increase the spectral range over which the gain/loss can be deduced.

Comparison of the gain spectra deduced using the two measurement schemes is shown in Fig. 14 at a current density of $350 \mathrm{~A} / \mathrm{cm}^{2}$ with an amplifier current density (JA) of $300 \mathrm{~A} / \mathrm{cm}^{2}$. Towards long wavelengths the two techniques show essentially identical results for the spectral shape and magnitude of the gain from the ensemble of QD ground states. The difference at shorter

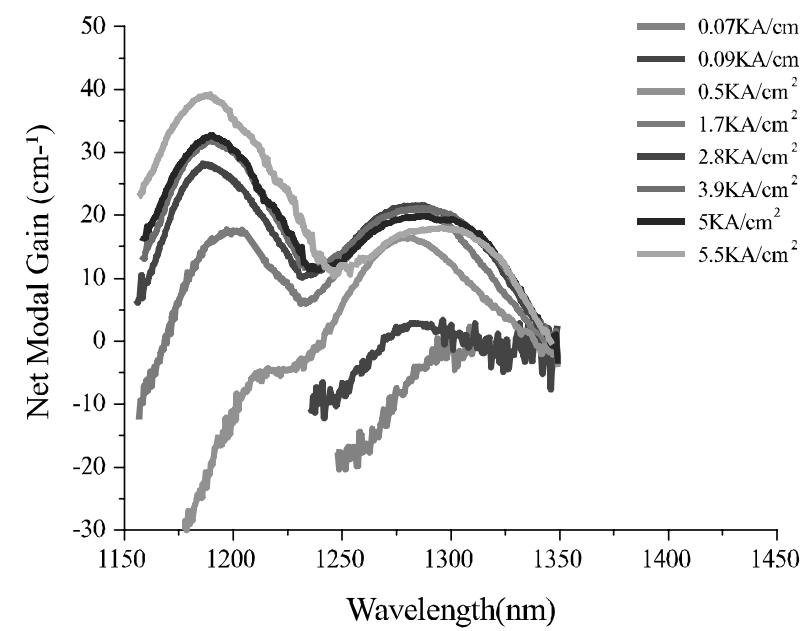

FIG. 13. HIGH CARRIER DENSITY HAKKI\&PAOLI NET MODAL GAIN SPECTRA AS A FUNCTION OF CARRIER DENSITY AT A FIXED 30OC LASER JUNCTION TEMPERATURE

Mehran University Research Journal of Engineering \& Technology, Volume 35, No. 4, October, 2016 [p-ISSN: 0254-7821, e-ISSN: 2413-7219] 
wavelengths suggests either the presence of unguided spontaneous emission or it may be due to the spatial in homogeneity of the sample. However, similar measurements for different materials where the length of the contact was varied showed similar results, suggesting that this difference is due to the absence of integrated mode filtering. Furthermore, the observation of a change in the excited state gain but not in ground state gain between the different spectra in Fig. 14 is unlikely to be due to spatial in homogeneity of the sample.

Fig. 15 plots the gain spectra vs. of current density for $\mathrm{SC}$ and IA with an amplifier current density JA $=1.42 \mathrm{kA} / \mathrm{cm}^{2}$. For these plots, the data is manually inspected and only the data where the signal can be discriminated from the noise floor are plotted. Wider ranges of the gain spectrum are measured using the IA method with identical data acquisition conditions. The difference becomes smaller as the current density in the sections being measured is increased, where the sections under test are no longer in loss, but are themselves in gain. For low current densities the difference is clearer, i.e. in terms of enhanced spectral range and with some current densities only being accessed through the use of the integrated amplifier. With this method the absorption measurement can be successfully performed under normal forward biased operating

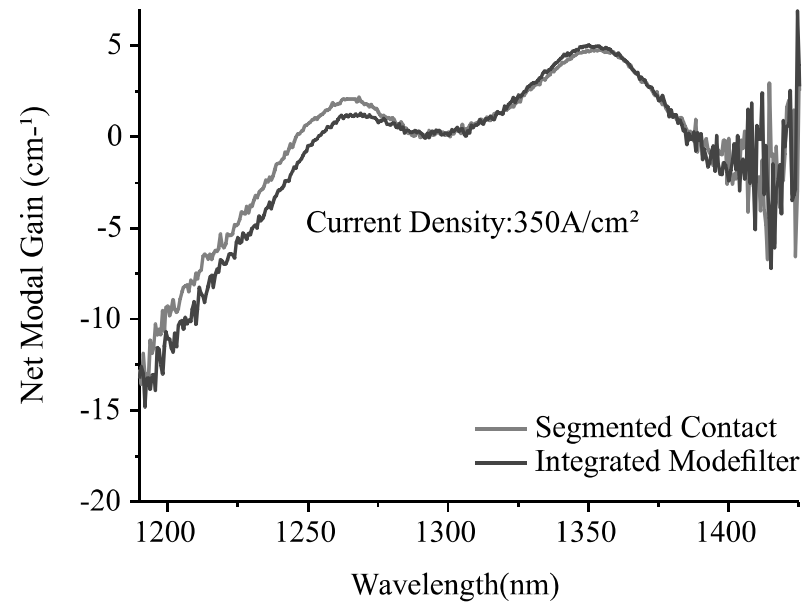

FIG. 14. NET MODAL GAIN SPECTRA AS A FUNCTION OF WAVELENGTH AT J $=350 A / \mathrm{cm}^{2}$ AND JA $=300 A / \mathrm{cm}^{2} F O R$ SEGMENTEDCONTACT AND INTEGRATED AMPLIFIER METHODS condition instead of open circuit or reverse biased conditions. The absorption peaks for the corresponding ground state and the excited state are clearly shown via averaging scheme as shown in Fig. 15. The observed evolution from absorption to the gain saturation with wider spectral ranges may help in understanding carrierdistribution [18-20] in ground- state and excited-state ensemble of states for the conditions of absorption and gain after transparency point without and with free carrier effects.

\section{CONCLUSION}

This paper reported a comparative analysis of the three gain measurement methods. For the purpose, multi-section, single mode devices were employed. During the analysis, experimental setups and conditions, spectral range accessibility and signal to noise ratios were compared. Before start of self heating effects all of the three techniques showed the same modal gain shapes and values for their peaks. SC method proved to be a better choice before the onset of self heating in terms of the internal loss measurement and signal to noise ratio. However, after start of self heating effects H\&P showed superiority over other methods in terms of giving an opportunity to analyze free carrier effects via fixing the junction temperature at a specific value of interest. The SC and IA methods were

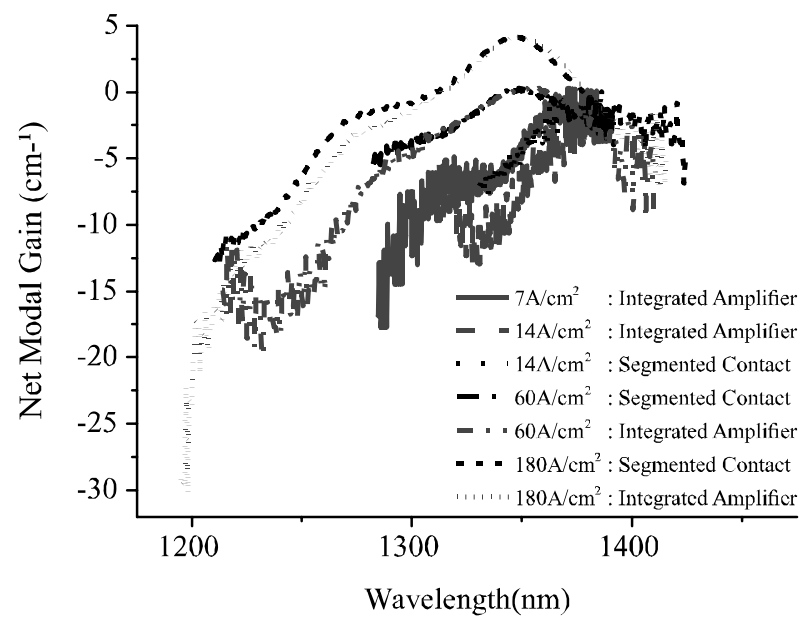

FIG. 15. NET MODAL GAIN SPECTRA AS A FUNCTION OF WAVELENGTH UTILIZING THE SEGMENTED- CONTACT ANDINTEGRATED-AMPLIFIER METHOD

Mehran University Research Journal of Engineering \& Technology, Volume 35, No. 4, October, 2016 [p-ISSN: 0254-7821, e-ISSN: 2413-7219] 
compared for low current density measurements. The IA method had been shown as the only possibility to access lower carrier densities with wider spectral ranges where the material usually operates in loss.

\section{ACKNOWLEDGEMENT}

The author is obliged to University of Engineering \& Technology, Kala Shah Kaku Campus, Lahore, Pakistan, for their support in writing this paper.

\section{REFERENCES}

[1] Greenwood, P.D.L., Childs, D.T.D., Kennedy, K., Groom, K.M., Hugues, M., Hopkinson, M., Hogg, R.A., Krstajic?, N., Smith, L.E., Matcher, S.J., Bonesi, M., MacNeil, S., and Smallwood, R., "Quantum Dot Super Luminescent Diodes for Optical Coherence Tomography: Device Engineering", IEEE Journal of Selected Topics in Quantum Electronics, Volume 16, No. 4, pp. 1015-1022, UK, April, 2010.

Rafailov, E.U., Cataluna, M.A., and Sibbett, W., "ModeLocked Quantum-Dot Lasers", Nature Photonics, Volume 1, pp. 395-401, US, January, 2007.

Otsubo, K., Hatori, N., Ishida, M., Okumura, S., Akiyama, T., Nakata,Y., Ebe, H., Sugawara. M., and Arakawa, Y., "Temperature-Insensitive Eye-Opening under $10-\mathrm{Gb} / \mathrm{s}$ Modulation of $1.3 \mu \mathrm{m}$ P-Doped Quantum-Dot Lasers without Current Adjustments", Japanese Journal of Applied Physics, Part-B, Volume 43, No. 8, pp. 1124-1126, Japan, July, 2004.

[4] Fathpour S., Mi, Z., Bhattacharya, P., Kovsh, A.R., Mikhrin, S.S., Krestnikov, I.L., Kozhukhov, A.V., and Ledentsov, N.N., "The Role of Auger Recombination in the Temperature-Dependent Output Characteristics

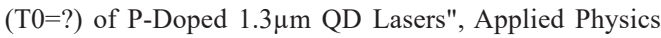
Letters, Volume 85, pp. 5164-5166, US, November, 2004.

[5] Shahid, H., Childs, D.T.D., Stevens, B.J., Hogg, R.A., and Smowton, P.M., "Comparison of Gain Measurement Techniques for 1.3?m Quantum Dot Lasers", Novel InPlane Semiconductor Lasers-X, Volume 7953, pp. 79531W, US, February, 2011.
[6] Wang, C., Gioannini, M., Montrosset, I., Even, J., and Grillot, F., "Influence of Inhomogeneous Broadening on the Dynamics of Quantum Dot Lasers", Physics and Simulation of Optoelectronic Devices-XXIII, Volume 9357, pp. 93570L, US, February, 2015.

[7] Schliwa, A., Schmeckebier, H., Stubenrauch, M., Spiegelberg, M., Bimberg, D., and Eisenstein, G., "Comparison of Dynamic Properties of Ground and Excited-State Emission in P-Doped InAs/GaAs QuantumDot Lasers", Applied Physics Letters, Volume 104, No. 18, pp. 181101, US, May, 2014.

[8] Wang, C., Osi'nski, M., Even, J., and Grillot, F., "PhaseAmplitude Coupling Characteristics in Directly Modulated Quantum Dot Lasers", Applied Physics Letters, Volume 105, No. 22, pp. 233103-21105, US, December, 2014

[9] Kabi, S., and Perera, A.U., "Effect of Quantum Dot Size and Size Distribution on the Inter-Sublevel Transitions and Absorption Coefficients of III-V Semiconductor Quantum Dot", Journal of Applied Physics, Volume 117, No. 12, pp. 124303, US, March, 2015.

[10] Bhowmick, S., Baten, M.Z., Frost, T., Ooi, B.S., and Bhattacharya, P., "High Performance InAs/ In $0.53 \mathrm{Ga} 0.23 \mathrm{~A} 10.24 \mathrm{As} / \mathrm{InP}$ Quantum Dot $1.55 ? \mathrm{~m}$ Tunnel Injection Laser", IEEE Journal of Quantum Electronics, Volume 50, No. 1, pp. 7, UK, January, 2014.

[11] Hakki, B.W., and Paoli T.L., "Gain Spectra in GaAs Double-Heterostructure Injection Lasers", Journal of Applied Physics, Volume 46, pp.1299, US, September, 2008.

[12] Blood, P., Lewis, G.M., Smowton, P.M., Summers, H., Thomson, J., and Lutti, J., "Characterization of Semiconductor Laser Gain Media by the Segmented Contact Method", IEEE Journal of Selected Topics in Quantum Electronic, Volume 9, pp. 1275-1282,UK, September, 2003.

[13] Shahid, H., Childs, D.T.D., Majid, M.A., Kennedy, K., Airey, R., Hogg, R.A., Clarke, E., Spencer, P., and Murray, R., "Gain Spectrum Measurement Using the Segmented Contact Method with an Integrated Optical Amplifier", Journal of Applied Physics, Volume115, pp. 163105, US, April, 2014. 
[14] Howe, P., LeRu, E.C., Clarke, E., Abbey, B., Murray, R., and Jones, T.S., "Quantification of Segregation and Strain Effects in InAs/GaAs Quantum Dot Growth", Journal of Applied Physics, Volume 98, pp. 113511, UK, December, 2005

[15] Majid, M.A., Childs, D.T.D., Shahid, H., Chen, S.C., Kennedy, K., Airey, R.J., Hogg, R.A., Clarke, E., Spencer, P., and Murray, R., "Excited State Bilayer Quantum Dot Lasers at 1.3um", Japanese. Journal of Applied Physics, Volume 50, pp. 04DG10, Japan, April, 2011.

[16] Xin, Y.C., Li,Y., Martinez, A., Rotter, T.J., Su, H., Zhang, L., Gray, A.L., Luong, S., Sun, K., Zou, Z., Zilko, J., Varangis, P.M., and Lester, L.F., "Optical Gain and Absorption of QDs Measured Using an Alternative Segmented Contact Method", IEEE Journal of Quantum Electronics, Volume 42, pp. 725-732, UK, July, 2006.
[17] Grundmann, M., and Bimberg, D., "Theory of Random Population for Quantum Dots", Physical Review-B, Volume 55, No. 15, pp. 9740, Germany, April, 1997.

[18] Agrawal, G.P., and Dutta, K.N., "Semiconductor Lasers", 2nd Edition, Chapter-2, Van Nostrand Reinhold, New York, USA, 1993.

[19] O'Driscoll, I., Hutchings, M., Smowton, P.M., and Blood, P., "Many-Body Effects in InAs/GaAs QD Laser Structures", Applied Physics Letters, Volume 97, pp. 141102, UK, October, 2010.

[20] Shahid, H., "Free Carrier Distribution Criterion in Quantum Dot Lasers", Mehran University Research Journal of Engineering \& Technology, Volume 35, No. 3, pp. 309-316, Jamhsoro, Pakistan, July, 2016. 